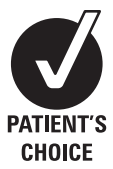

See Editorial commentary, p 1185

- Additional material is published online only. To view these files please visit the journal online (http://jnnp.bmj. com)

'Primary Care Research Group, Peninsula College of Medicine and Dentistry (PCMD)

University of Exeter, Exeter, UK 2PenCLAHRC, Peninsula College of Medicine and Dentistry, University of Exeter, Exeter, UK ${ }^{3}$ NIHR Research Design Service, Musgrove Park Hospital,

Taunton, UK

${ }^{4}$ College of Life and Environmental Sciences, University of Exeter, Exeter, UK

Correspondence to Dr V Goodwin, PCMD, Veysey Building, Salmon Pool Lane, Exeter EX2 4SG, UK: victoria.goodwin@pms.ac.uk

Received 11 July 2011 Accepted 15 July 2011 Published Online First 19 August 2011

\title{
An exercise intervention to prevent falls in people with Parkinson's disease: a pragmatic randomised controlled trial
}

\author{
Victoria A Goodwin, ${ }^{1}$ Suzanne H Richards, ${ }^{1}$ William Henley, ${ }^{2}$ Paul Ewings, ${ }^{3}$ \\ Adrian H Taylor, ${ }^{4}$ John L Campbell ${ }^{1}$
}

\section{ABSTRACT}

Objectives To compare the effectiveness of an exercise programme with usual care in people with Parkinson's disease (PD) who have a history of falls.

Design Pragmatic randomised controlled trial.

Setting Recruitment was from three primary and four secondary care organisations, and PD support groups in South West England. The intervention was delivered in community settings.

Participants People with PD, with a history of two or more falls in the previous year, who were able to mobilise independently.

Intervention 10 week, physiotherapy led, group delivered strength and balance training programme with supplementary home exercises (intervention) or usual care (control).

Main outcome measure Number of falls during the (a) 10 week intervention period and (b) the 10 week followup period.

Results 130 people were recruited and randomised (64 to the intervention; 66 to usual care). Seven participants (5.4\%) did not complete the study. The incidence rate ratio for falls was $0.68(95 \% \mathrm{Cl} 0.43$ to $1.07, \mathrm{p}=0.10)$ during the intervention period and $0.74(95 \% \mathrm{Cl} 0.41$ to 1.33, $p=0.31$ ) during the follow-up period. Statistically significant between group differences were observed in Berg balance, Falls Efficacy Scale-International scores and recreational physical activity levels.

Conclusions The study did not demonstrate a statistically significant between group difference in falls although the difference could be considered clinically significant. However, a type 2 error cannot be ruled out. The findings from this trial add to the evidence base for physiotherapy and exercise in the management of people with PD.

Trial registration ISRCTN50793425.

\section{INTRODUCTION}

Up to two-thirds of people with Parkinson's disease (PD) experience falls each year ${ }^{1}$ compared with a third of community dwelling older people. ${ }^{2}$ The consequences of falling are widespread, impacting on patients, families, and health and social care organisations. Falls and associated injuries are the main reason for hospital admissions among this population, resulting in extended hospital stays. ${ }^{3}$ The psychosocial consequences of falling, such as fear of falling, impact on everyday life due to activity and dependency on others. ${ }^{4} 5$ Recent surveys have suggested that despite most people with PD experiencing problems with mobility, activities of daily living and falls, many do not access rehabilitation services. ${ }^{6}$

To date, few trials have examined the effectiveness of interventions aimed at reducing falls among people with $\mathrm{PD}$, and there is currently no evidence of benefit. ${ }^{7}$ One UK trial, ${ }^{9}$ involving 142 people with $\mathrm{PD}$, compared a 6 week, home based physiotherapy programme with usual care but no significant reduction in the risk of falling over 6 months was observed (risk ratio $0.94,95 \%$ CI 0.77 to 1.15 ). In contrast, there is a wealth of evidence endorsing the benefits of exercise programmes, specifically strength and balance training, in reducing falls among community dwelling older people. ${ }^{10} 11$ However, it is as yet unclear whether these exercise interventions would be equally effective among those with PD.

In this paper, we report the findings of a trial evaluating the effectiveness of a group delivered strength and balance training programme with supplementary home exercises, compared with usual care, on falls in patients with PD who have a history of falling. A parallel economic evaluation was undertaken and is reported separately (Fletcher et al, unpublished).

\section{METHODS}

\section{Design}

A pragmatic, parallel group randomised controlled trial was conducted in South West England. Ethics approval for the trial was given by the Devon and Torbay Local Research Ethics Committee.

\section{Procedures}

Potential participants were identified from: (a) specialist PD clinicians and DeNDRoN (Dementia and Neurodegenerative Disease Research Network) research nurses from four acute hospital trusts and one community trust; (b) general practices in three primary care organisations, identified by the Primary Care Research Network; and (c) local PD support groups.

Inclusion criteria included a diagnosis of idiopathic PD as confirmed by a PD specialist (geriatrician or neurologist) using UK Brain Bank criteria, ${ }^{12}$ a self-reported history of recurrent falls (two or more) in the preceding year, the ability to mobilise independently indoors, with or without a walking aid, and being resident in Devon or registered with a Devon general practitioner. Potential participants were excluded if they needed supervision or assistance to mobilise indoors, had a significant comorbidity or symptoms that 
affected ability or safety to exercise (eg, unstable angina, significant postural hypotension, severe pain) or were unable to follow written or verbal instructions in English.

Participants were assessed at baseline in geographically determined cohorts to minimise participant travel for those allocated to the exercise group. Each participant provided written consent before completing baseline assessments. Participants then commenced recording falls prospectively in weekly diaries for a 10 week baseline period. Once a cohort had been recruited and assessed, telephone randomisation procedures were used, using a service independent from the study data collection, for allocation assignment. The randomisation sequence was created using computer generated random number tables, with 1:1 allocation of individuals to either the intervention group or the control group. The research team were not informed of the random number sequences so as to prevent prediction of allocation. Due to the nature of the intervention it was not possible to blind the participants to allocation. Participants were informed of their allocation in writing by the research team before commencement of the intervention.

\section{Interventions}

The intervention comprised 10 once weekly group exercise sessions, with twice weekly home exercises, commencing 10 weeks after the initial assessment. For each group, sessions were delivered in community settings, on the same day and time each week, by one of five National Health Service physiotherapists, with experience of working with older people and those with PD. The group exercise programme included a $10 \mathrm{~min}$ warm up, $40 \mathrm{~min}$ of strength and balance training exercises, and a 10 min cool down (table 1). The menu of exercises was drawn from an effective falls prevention programme. ${ }^{13} 14$ The physiotherapists tailored and progressed the exercises to meet indi- vidual capabilities - for example, adjusting the level of resistance for strength exercises, number of repetitions or the level of intensity of balance exercises. Participants were also provided with an individually tailored home exercise programme to complete twice a week. A register of attendance was maintained, and participants self-reported home exercise completion in a diary. The physiotherapists were not involved in providing usual clinical care to the study participants.

All participants received usual care at the discretion of the clinical team. This team was blinded to participant allocation. Usual care could include medical and medication management, physiotherapy (eg, exercise, advice, provision of walking aids, gait training), occupational therapy (eg, modification of home hazards, provisions of aids or adaptations) or speech therapy.

\section{Intervention fidelity}

To standardise the intervention, each physiotherapist was provided with a training session and exercise manual, and was observed in practice delivering one of the group sessions by a clinical researcher to monitor fidelity. The researcher provided written and verbal feedback regarding content, safety, effectiveness and personal performance. No further training was required as all staff were deemed to be following the protocol, possibly due to individual exercises being commonly used in clinical practice. It was acknowledged that there would be some differences in delivery style between the different physiotherapists. However, this is usual in routine clinical practice, and therefore consistent with the pragmatic nature of the study.

\section{Outcome measures}

Falls and fall related injuries were self-reported and collected via weekly diaries and returned in prepaid envelopes by the study participants each week for 30 weeks. A fall was defined as 'an

Table 1 Examples of exercises used in the programme ${ }^{13}$

\begin{tabular}{|c|c|c|}
\hline & Exercise examples* & Modifications and progressions \\
\hline \multirow[t]{2}{*}{ Warm up — circulation boosters } & Marching & $\begin{array}{l}\text { Reduce hand support, increase range of movement, } \\
\text { add arm swing }\end{array}$ \\
\hline & Arm swings & Increase range of movement \\
\hline \multirow[t]{4}{*}{ Warm up-joint mobility } & Shoulder circles & Increase range of movement \\
\hline & Side bends & - \\
\hline & Trunk twists & Reduce hand support \\
\hline & Ankle mobiliser & Increase range of movement \\
\hline \multirow[t]{3}{*}{ Warm up and cool down-stretches } & Calf & - \\
\hline & Hamstrings & - \\
\hline & Chest & - \\
\hline \multirow[t]{7}{*}{ Balance } & Side steps & Widen step, reduce hand support, double step \\
\hline & Side taps & Widen step, reduce hand support, add arm curl \\
\hline & Side sway & Add knee bend, reduce hand support, add arm swing \\
\hline & Lunges (all directions) & $\begin{array}{l}\text { Reduce support, increase range of movement, reduce depth } \\
\text { of movement, increase repetitions }\end{array}$ \\
\hline & Toe walk & Increase repetitions, reduce support \\
\hline & Heel walk & Increase repetitions, reduce support \\
\hline & Tandem walk & Increase repetitions, reduce support \\
\hline \multirow[t]{6}{*}{ Strengthening } & Heel raise & Increase repetitions, reduce hand support, reduce base of support \\
\hline & Toe raise & Increase repetitions, reduce hand support, reduce base of support \\
\hline & Sit to stand & Increase repetitions, reduce support \\
\hline & Seated leg press (with band) & Increase repetitions, increase band resistance \\
\hline & $\begin{array}{l}\text { Seated upper back strengthener } \\
\text { (with band) }\end{array}$ & Increase repetitions, increase band resistance \\
\hline & $\begin{array}{l}\text { Seated outer leg strengthener } \\
\text { (with band) }\end{array}$ & Increase repetitions, increase band resistance \\
\hline
\end{tabular}

*Done in supported standing (with seated alternative) unless stated. 
unexpected event resulting in coming to rest at a lower level than intended'. ${ }^{15}$ Prospective baseline falls data were established using the first 10 weeks of diaries prior to the commencement of the intervention period. The primary outcomes were the number of falls during (a) the 10 week group intervention period and (b) the 10 week follow-up period.

Secondary outcomes, identified from pilot work ${ }^{16}$ and guidance on datasets for falls prevention trials, ${ }^{15}$ were recorded by a single researcher in the patient's own home at the same time of day to minimise the effects of medication and motor fluctuations. Assessments were completed at three time points: baseline, post-intervention and follow-up (10 weeks post-intervention). Secondary outcomes were Falls Efficacy Scale-International, ${ }^{17}$ EuroQOL-5D, ${ }^{18}$ Phone-FITT (household and recreational physical activity), ${ }^{19}$ Berg balance scale ${ }^{20}$ and Timed up and go (see supplementary data, available online only). ${ }^{21}$ It was not possible to blind the outcome assessor to participant allocation. To minimise possible observer bias, all secondary outcome assessments were undertaken without reference to previous assessment data.

\section{Sample size}

The sample size calculation was based on a pilot study, using a pre-post design with no control group, of 11 patients whose falls were recorded over a 10 week period. ${ }^{16}$ One subject experienced 100 falls during that time and was excluded as an outlier. The range of falls was 6-63 in 10 weeks (median 20; mean 23 (SD 18)). Based on previous study findings, ${ }^{22}$ calculations indicated that to demonstrate a conservative $30 \%$ reduction in falls $(\alpha=0.05$ and $80 \%$ power), 92 subjects were required in both the intervention and control groups. At the time of planning the trial there were insufficient data to provide robust estimates of the necessary parameters for a sample size calculation based on negative binomial regression (see supplementary data, available online only) and, for simplicity, the calculation was based on a t test. We anticipated that a total study population of 248 participants would be required, allowing for a potential attrition of $25 \%$.

\section{Analysis}

Comparison of the fall rate between the two groups during the intervention and follow-up periods was undertaken using negative binomial regression ${ }^{23}$ adjusting for baseline falls to produce an incidence rate ratio (IRR) using STATA (V.9.2). The potential clustering effects of geographical group and physiotherapist were examined using fixed effects models. Clustering is an important consideration in trials where, for example, a number of individuals deliver an intervention, thus impacting on the assumption of independence. ${ }^{24}$ The effect of disease and changes to PD medication during the trial were examined. Logistic regression was used to establish the risk of falling (adjusted for baseline fall status) and the risk of sustaining an injury (adjusted for baseline injury status) between groups. Missing falls data were imputed when fewer than five diaries were missing in a 10 week data collection period, by using the mean of the falls data from the immediately previous and subsequent diaries. Secondary outcomes, measured at the end of the intervention period and at the 10 week follow-up, were compared between groups using ANCOVA controlling for baseline values, with transformation of data where necessary to meet the assumption of normal distributed residuals. All secondary outcome analyses were performed using SPSS (V.15). Data were analysed using the full analysis set, defined as "the analysis set which is as complete as possible and as close as possible to the intention to treat ideal'. ${ }^{25}$

\section{RESULTS}

Between May 2007 and November 2008, 343 people were approached to take part in the trial (figure 1). One hundred and thirty people $(40 \%)$ met the selection criteria and consented to participate. Seven participants (5\%) did not complete the followup assessment. Follow-up continued until June 2009.

The intervention group $(n=64)$ and the control group $(n=66)$ participants had similar baseline characteristics (table 2) with the exception of the proportion taking dopamine agonists and receiving physiotherapy at baseline. Slightly more men than women participated in the study, reflecting the gender demographics of the condition. All 130 participants in the trial were white and all, except two, were British. Table 3 presents baseline outcome data as medians (IOR) and means (SD).

There were 15 geographical cohorts, with the exercise groups including between three and seven participants. The groups were attended for a median (IRQ) of 8 sessions (3, 9), with a mean (SD) of 6 sessions (3.6). Thirty-three people (51.6\%) attended 8 or more sessions, and nine people attended none $(14.1 \%)$. Home exercises were undertaken a median (IOR) of twice $(1,3)$ and a mean (SD) of twice a week (1) for the 20 weeks of follow-up. Five participants reported doing no home exercises. No adverse events occurred during the exercise sessions. A total of $289 / 3900$ (7.4\%) of weekly falls diaries were

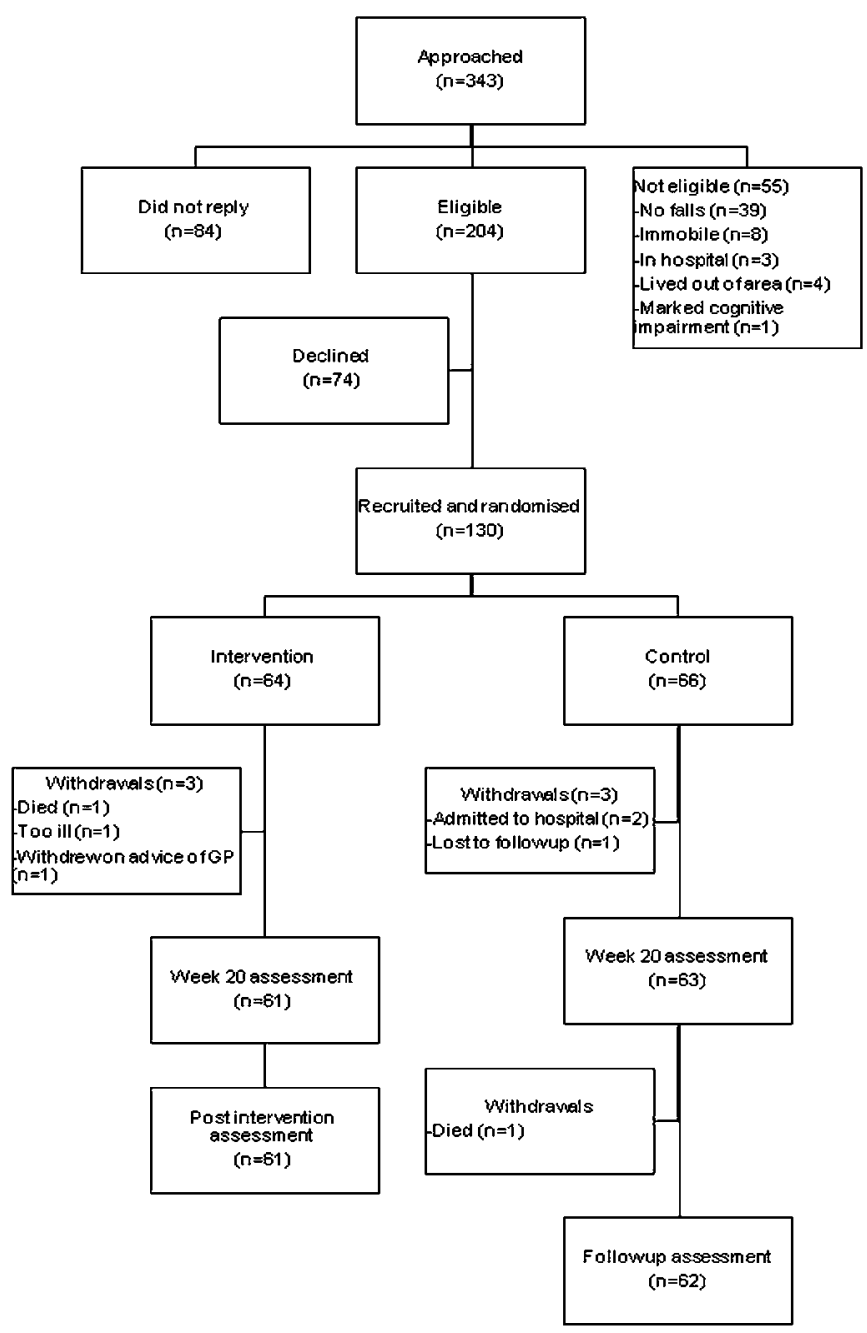

Figure 1 Flow chart of recruitment, allocation and follow-up of study participants. 
Table 2 Baseline demographic and clinical characteristics for intervention and control group participants

\begin{tabular}{lcc}
\hline & $\begin{array}{l}\text { Intervention } \\
(\mathbf{n}=64)\end{array}$ & $\begin{array}{c}\text { Control } \\
(\mathbf{n}=66)\end{array}$ \\
\hline Age (years) & $72.0(8.6)$ & $70.1(8.3)$ \\
Mean (SD) & $50-87$ & $53-89$ \\
Range & $39(60.9)$ & $35(53.0)$ \\
No of males (\%) & $9.1(6.4)$ & $8.2(6.4)$ \\
Years since diagnosis of PD (mean (SD)) & $2.6(0.9)$ & $2.4(0.9)$ \\
Hoehn and Yahr stage (mean (SD)) & $4(6)$ & $9(14)$ \\
Stage 1 (n (\%)) & $31(48)$ & $28(42)$ \\
Stage 2 (n (\%)) & $16(25)$ & $21(32)$ \\
Stage 3 (n (\%)) & $13(20)$ & $8(12)$ \\
Stage 4 (n (\%)) & $14(22)$ & $19(29)$ \\
Living arrangements (n (\%)) & $48(75)$ & $44(67)$ \\
Alone & $1(2)$ & $2(3)$ \\
With partner & $1(2)$ & $1(2)$ \\
With family/friends & $59(92)$ & $65(99)$ \\
Residential home & $39(61)$ & $27(41)$ \\
No (\%) taking levodopa & $10(16)$ & $15(23)$ \\
No (\%) taking dopamine agonist & $23(36)$ & $23(35)$ \\
No (\%) taking monoamine oxidase inhibitor & $21(33)$ & $25(38)$ \\
No (\%) with orthopaedic comorbidity & $7(11)$ & $10(15)$ \\
No (\%) with cardiac comorbidity & $7(11)$ & $2(3)$ \\
No (\%) with mental health comorbidity & & \\
No (\%) receiving physiotherapy for PD & & \\
\hline PD, Parkinson's disease & &
\end{tabular}

missing. Missing items on secondary outcome questionnaires accounted for $0.6 \%$ of the total.

Over the 20 weeks of post-baseline data collection, 1507 falls were reported by intervention group participants $(n=61)$, with 3981 falls reported by controls $(n=64)$. Figure 2 presents data on the total number of falls reported in each group for each data collection period. Median (range) falls during the intervention and follow-up periods were $3(0,398)$ and $2.5(0,49)$ for the intervention group and $6(0,677)$ and $4(0,678)$ for the control group. The IRR was $0.68(95 \%$ CI 0.43 to $1.07, p=0.10)$ during the intervention period and 0.74 ( $95 \%$ CI 0.41 to $1.33, p=0.31)$ during the 10 week follow-up period. No significant effect was observed for disease stage (IRR $0.97,95 \%$ CI 0.74 to 1.26 , $\mathrm{p}=0.79)$. Thirty-one $(51 \%)$ of the intervention participants and 34 (54\%) of the controls changed their PD medication during the trial. No statistically significant interaction was observed between allocation and PD medication changes (IRR 0.44, 95\% CI 0.17 to $1.15, p=0.09$ ). Including the effect of clustering due to geographical group indicated a significant effect during the intervention period (IRR $0.62,95 \%$ CI 0.40 to $0.97, p=0.04$ ) in favour of the exercise programme but there was no effect for clustering during follow-up (IRR $0.81,95 \%$ CI 0.45 to 1.47 , $\mathrm{p}=0.48$ ). No clustering effect for physiotherapist was observed. Nine intervention group and nine control participants reported no falls. No statistically significant differences were found between the study groups for risk of falling (OR 0.70, 95\% CI 0.28 to $1.74, p=0.44$ ) or the risk of injury (OR $0.59,95 \%$ CI 0.26 to $1.35, p=0.21$ ). During the trial, only one fracture was reported by a control group participant who sustained a pelvic fracture.

Table 4 presents the secondary outcome measures at baseline, post-intervention and follow-up, stratified by group allocation. Significant between group differences were observed in Berg balance and Falls Efficacy Scale-International scores post-intervention, and in Berg and recreational physical activity levels at
Table 3 Median (IOR) and mean (SD) baseline outcome measures for the intervention and control participants

\begin{tabular}{lll}
\hline & $\begin{array}{l}\text { Intervention } \\
(\mathbf{n}=64)\end{array}$ & $\begin{array}{c}\text { Control } \\
(\mathbf{n}=66)\end{array}$ \\
\hline $\begin{array}{l}\text { No of people sustaining } \\
\text { no falls }\end{array}$ & 9 & 12 \\
No of falls (range) & $1590(0-531)^{*}$ & $1863(0-577) \dagger$ \\
$\quad$ Median (IQR) falls & $6.5(1.3-18.5)^{*}$ & $6.5(1.0-26.5) \dagger$ \\
$\quad$ Mean (SD) & $26.5(77.2)^{*}$ & $29.1(78.1) \dagger$ \\
Median (IQR) FES-I score & $30.0(23.2-39.0)$ & $32.0(26.0-41.3)$ \\
$\quad$ Mean (SD) & $31.6(9.6)$ & $33.4(10.2)$ \\
Median (IOR) EQ-5D score & $0.7(0.6-0.8)$ & $0.7(0.6-0.8)$ \\
$\quad$ Mean (SD) & $0.7(0.2)$ & $0.7(0.2)$ \\
Median (IOR) Phone-FITT & $16.0(9.0-25.0)$ & $19.0(10.0-26.6)$ \\
household physical & & \\
activity levels & $17.5(11.5)$ & $17.7(10.6)$ \\
$\quad$ Mean (SD) & $11.0(5.0-16.0)$ & $10.0(5.5-18.0)$ \\
Median (IQR) Phone-FITT & & \\
recreational physical & & \\
activity levels & $11.6(8.7)$ & $12.1(9.8)$ \\
$\quad$ Mean (SD) & $29.0(16.3-39.0)$ & $30.0(20.5-40.0)$ \\
Median (IOR) Phone-FITT total & & \\
physical activity & $29.1(15.2)$ & $30.1(15.1)$ \\
$\quad$ Mean (SD) & $7.5(6.0-9.0)$ & $8.0(6.0-10.0)$ \\
Median (IQR) physical self-worth & $7.5(2.2)$ & $8.0(2.4)$ \\
$\quad$ Mean (SD) & $44.0(36.3-48.8)$ & $43.5(37.0-51.0)$ \\
Median (IQR) Berg balance & $41.6(10.7)$ & $43.4(8.9)$ \\
$\quad$ Mean (SD) & $16.1(11.9-21.7)$ & $16.3(11.8-24.7)$ \\
Median (IQR) Timed up and go & $19.2(10.8)$ & $20.9(15.0)$ \\
$\quad$ Mean (SD) & & \\
\hline
\end{tabular}

${ }^{*} \mathrm{n}=60 ; \mathrm{n}=62$ (due to missing data).

FES-I, Falls Efficacy Scale-International.

the 10 week follow-up, in favour of the intervention group. No other between group differences were established.

\section{DISCUSSION}

Principal findings

This is the first trial undertaken with people with PD to report the rate of falls as an outcome. We found a statistically nonsignificant reduction in the rate of falls among people with $\mathrm{PD}$ undertaking an exercise intervention. However, when adjusting for geographical group, a statistically significant difference was observed during the intervention period, possibly due to different therapeutic practices between sites, indicating that

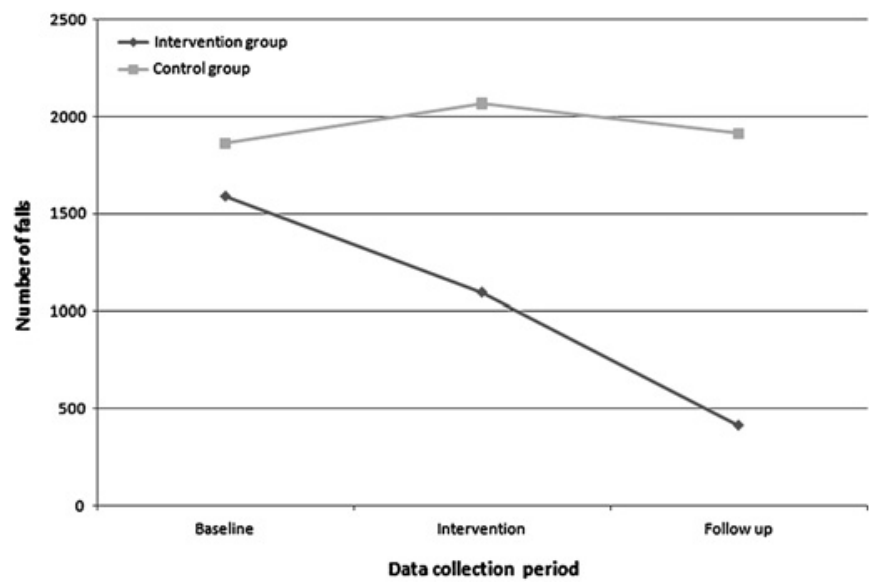

Figure 2 Graphical representation of the total number of falls during each time period for the intervention and control groups. 
potential clustering is an important consideration in studies of this nature. However, we failed to achieve the predicted sample size, and the 95\% CIs around our estimates of effect are wide, such that we cannot rule out a type II error. Although caution is required in interpreting our findings due to being underpowered, from a clinical perspective we believe that the between group differences in falls rates of $32 \%$ during the intervention and $26 \%$ in the 10 week post-intervention period are important. While our study cannot prove there are benefits, in terms of reducing falls rates, arising from the exercise programme neither can we rule out such benefits. While failing to achieve statistical significance, our findings are comparable with the findings from a recent Cochrane review for the prevention of falls in older people $e^{7}$ that reported that those at high risk of falling experienced a $25 \%$ reduction in falls rate following an exercise intervention (IRR $0.75,95 \%$ CI 0.62 to 0.89 ). In addition, we have shown that significant benefits can be achieved with regards to balance, fear of falling and recreational physical activity levels.

\section{Study strengths and limitations}

We employed prospective data collection relating to the number of falls, considered to be the standard method of monitoring falls. ${ }^{15}$ The analysis of falls, as discrete recurrent events using negative binomial regression, is an appropriate method but is infrequently undertaken in studies of falls prevention among older people $e^{23}$ and was not used in a trial of falls prevention among people with PD. ${ }^{9}$ The European Prevention of Falls Network (ProFaNE) has made recommendations regarding data that should be collected routinely in falls prevention trials to facilitate comparison between studies and meta-analyses.
Suggested outcome domains include falls (rate and risk), fall injury, psychological consequences of falling, generic health related quality of life and physical activity, ${ }^{15}$ all of which were collected as part of our trial. Attendance at the group sessions and self-reported home exercise completion was comparable to Allen et $a l^{26}$ who reported $70 \%$ adherence to a 6 month minimally supervised home based strength and balance programme. Including an unsupervised home programme as part of an intervention reduces the burden on resource limited physiotherapy services, promotes autonomy and enables patients to increase their physical activity levels. A range of opportunities to participate in exercise interventions, such as groups or individually delivered sessions, should be available in practice in order to meet the needs of differing patient circumstances and motivations. $^{27} 28$

There were a number of limitations to this study. Ideally, a longer follow-up of 1 year should have been employed in our study but this was not possible within the confines of funding. We also failed to recruit the number of participants indicated by the a priori sample size calculation, despite the support from NIHR research networks in assisting with recruitment. Difficulties in recruitment have been reported in a similar study in the UK. ${ }^{9}$ While we did not achieve our target, the study had a substantially lower withdrawal rate $(5 \%)$ compared with our predicted attrition of $25 \%$. Trials evaluating exercise interventions with people with $\mathrm{PD}$ have reported withdrawals, with up to $13 \%$ (7/56) withdrawing from a 1 year study of Oigong. ${ }^{29}$ A further limitation of our study is the potential bias associated with a lack of assessor blinding of the outcomes. However, as the primary outcome was self-reported, this was not achievable, particularly as it was not possible to blind participants due to the nature of

Table 4 Median (IQR) secondary outcome scores with transformations used, mean differences in transformed data (95\% Cls) and $\mathrm{p}$ values

\begin{tabular}{|c|c|c|c|c|c|}
\hline & \multirow[b]{2}{*}{$\begin{array}{l}\text { Intervention ( } \mathrm{n}=61 \text { ) } \\
\text { Median (IOR) scores }\end{array}$} & \multirow{2}{*}{$\begin{array}{l}\text { Control }(\mathrm{n}=63 *) \\
\text { Median (IOR) scores }\end{array}$} & \multicolumn{3}{|c|}{ Between group difference } \\
\hline & & & $\begin{array}{l}\text { Transformation } \\
\text { applied }\end{array}$ & $\begin{array}{l}\text { Mean difference } \\
\text { in transformed } \\
\text { scores }(95 \% \mathrm{Cl})\end{array}$ & p Value \\
\hline \multicolumn{6}{|l|}{ FES-I } \\
\hline Baseline & $30.0(23.3-39.0)$ & $32.0(26.0-41.3)$ & Log & & \\
\hline Post-intervention & $29.0(24.0-34.0)$ & $35.0(27.0-41.0)$ & & $-0.09(-0.18$ to -0.01$)$ & 0.04 \\
\hline Follow-up & $29.0(23.0-38.0)$ & $32.0(25.0-42.0)$ & & $-0.05(-0.14$ to 0.04$)$ & 0.27 \\
\hline \multicolumn{6}{|l|}{ EQ-5D } \\
\hline Baseline & $0.7(0.6-0.8)$ & $0.7(0.6-0.8)$ & Square root & & \\
\hline Post-intervention & $0.7(0.6-0.8)$ & $0.7(0.6-0.8)$ & & $-1.40(-3.63$ to 3.48$)$ & 0.22 \\
\hline Follow-up & $0.8(0.6-1.0)$ & $0.7(0.5-0.9)$ & & $-0.55(-4.4$ to 3.34$)$ & 0.78 \\
\hline \multicolumn{6}{|c|}{ Household physical activity } \\
\hline Baseline & $16.0(9.0-25.0)$ & $19.0(10.0-26.6)$ & Square root & & \\
\hline Post-intervention & $16.0(8.0-24.5)$ & $21.0(13.0-27.0)$ & & $-0.25(-0.70$ to 0.19$)$ & 0.26 \\
\hline Follow-up & $17.0(8.0-26.5)$ & $22.0(10.5-28.0)$ & & $-0.25(-0.70$ to 0.19$)$ & 0.26 \\
\hline \multicolumn{6}{|c|}{ Recreational physical activity } \\
\hline Baseline & $11.0(5.0-16.0)$ & $10.0(5.5-18.0)$ & Square root & & \\
\hline Post-intervention & $12.0(8.0-21.0)$ & $11.0(4.0-19.0)$ & & $0.43(-0.05$ to 0.90$)$ & 0.08 \\
\hline Follow-up & $13.0(8.0-22.0)$ & $10.5(5.0-17.3)$ & & 0.61 (0.12 to 1.10$)$ & 0.02 \\
\hline \multicolumn{6}{|l|}{ Berg balance scale } \\
\hline Baseline & $44.0(36.3-48.8)$ & $43.5(37.0-51.0)$ & $\log$ & & \\
\hline Post-intervention & $49.0(39.0-53.5)$ & $44.0(36.0-52.0)$ & & $-0.34(-0.54$ to -0.14$)$ & $<0.01$ \\
\hline Follow-up & $48.0(41.0-53.0)$ & $46.0(36.5-51.5)$ & & $-0.43(-0.63$ to -0.24$)$ & $<0.01$ \\
\hline \multicolumn{6}{|l|}{ Timed up and go } \\
\hline Baseline & $16.1(11.9-21.7)$ & $16.3(11.8-24.7)$ & Reciprocal & & \\
\hline Post-intervention & $16.4(12.2-22.2)$ & $17.9(11.7-23.6)$ & & $0.00(0.00$ to 0.00$)$ & 0.95 \\
\hline Follow-up & $15.2(12.2-22.0)$ & $16.1(12.0-22.6)$ & & $0.01(-0.01$ to 0.01$)$ & 0.72 \\
\hline
\end{tabular}

${ }^{*}$ All follow-up scores based on $\mathrm{n}=62$ participants.

FES-I, Falls Efficacy Scale-International. 
the intervention. A lack of blinding in pharmacological studies can result in inflated effect sizes ${ }^{30}$ but the impact in studies of rehabilitation remains unclear. A final limitation, the lack of ethnic diversity among the study participants, reflects the population of South West England, particularly among older people. ${ }^{31}$ This may have implications for the generalisability of our findings to areas with greater ethnic diversity.

\section{Generalisability}

Using several physiotherapists in this trial was considered a strength, as clinical practice interventions would be delivered by a range of physiotherapists with differing attributes. As the intervention was tailored to the individual participants, steps were taken to ensure a standardised approach was taken in the form of training and monitoring. ${ }^{32}$ This pragmatic approach is important when translating research interventions into clinical practice.

Exercise interventions have been found to be effective at improving balance in people with $\mathrm{PD}^{8}$ and we observed significant between group differences in Berg balance scores at the end of the intervention period, which were maintained at follow-up. The improvement in balance scores by 5 points for intervention participants is consistent with the minimal detectable change of between 4 and 7 points. ${ }^{33}$ Lamb et al ${ }^{15}$ indicated that there is a lack of consensus regarding minimal clinically important differences in relation to the common dataset measures for falls trials. Ashburn et al ${ }^{9}$ found no between group differences using the Berg balance scale although they did find a difference in Functional Reach scores. Allen et al ${ }^{26}$ failed to identify a between group difference in a fall risk score (including a balance component). The different findings between studies could be attributed to the differing models of exercise delivery.

We failed to find any differences in the Timed up and go, and although the intervention component did not include mobility training, the programme did include participants practising rising from a chair and turning; both components of the Timed up and go. Interestingly, among studies with people with PD that have evaluated movement and exercise interventions, ${ }^{34} 35$ none has identified significant improvements in the Timed up and go, despite it being a recommended outcome to use in people with PD. ${ }^{36}$ However, this may relate to the fact that this measure was not the primary outcome and the studies were not powered to detect differences. Similarly, the study was not powered to observe differences in health related quality of life, which may explain the difference to findings from other studies of exercise with people with PD. ${ }^{89}$

\section{Implications for practice}

Around half of people with PD have never seen a physiotherapist $^{6}$ and services for this group of patients are often lacking, particularly in community settings. ${ }^{37}$ A reason for the lack of services in the past has been the paucity of research supporting changes to policy and practice. This trial, however, provides evidence of the benefits of a physiotherapy delivered strength and balance training programme for people with PD.

\section{Future research}

While we targeted the intervention at those who had already fallen, there may be a need to also examine the impact of falls prevention programmes with those people with $\mathrm{PD}$ who have not fallen. We would also recommend that evaluations be undertaken with a wider demographic population in terms of ethnicity. Also, participants in future trials should be followed- up for at least a year. ${ }^{15}$ Qualitative studies, process evaluations and economic evaluations should also form part of any further programmes of work. ${ }^{38}$ A parallel economic study was undertaken as part of this trial and this is reported separately. Given the paucity of studies examining falls prevention among people with $\mathrm{PD}$ and the difficulties with recruitment, further work is required to establish effectiveness using larger sample sizes. Two studies of falls prevention in PD are currently underway in Australia with both aiming for sample sizes of around 200 participants. ${ }^{39} 40$ In the current economic climate, rather than proposing a further randomised controlled trial, it may be more appropriate to undertake meta-analyses examining the overall effect sizes in relation to falls rate and risk once these studies have completed data collection.

\section{CONCLUSION}

The exercise programme delivered in this trial resulted in a nonstatistical, but potentially clinically significant, difference in falls among people with PD compared with usual care. This said, a type 2 error, due to recruitment difficulties, cannot be ruled out. However, statistically significant differences in balance, fear of falling and recreational physical activity were observed. These findings add to the growing evidence base for exercise and physiotherapy led interventions for people with PD. However, further work is required before firm conclusions can be drawn in terms of the effectiveness of exercise interventions for preventing falls among this group of patients.

Acknowledgements We would like to thank Dr Finbarr Martin and Dr Dawn Skelton for their advice in developing the study protocol and independently overseeing the research, Later Life Training for their permission to use the Postural Stability Instructors exercise manual, the physiotherapists Lianne Balk, Chris Barker, Angela Moore, Jo Richardson and Carla Tucker, and, Zoe Silk for her assistance with data management.

Funding VG was funded to undertake this research as part of an NIHR Researcher Development Award (grant No RDA/02/06/41). This article presents independent research commissioned by the National Institute for Health Research (NIHR). The views expressed in this publication are those of the authors and not necessarily those of the NHS, the NIHR or the Department of Health.

Competing interests PCMD (VG, WH) and University of Exeter (AT) received funding from NIHR to undertake this research.

Ethics approval Ethics approval was provided by Devon and Torbay Local Research Ethics Committee.

Contributors Design of the study (all authors); data collection (VG); data analysis and interpretation (all authors); drafted paper (VG); revised paper for intellectual content (SR, WH, PE, AT, JC); guarantor of data (VG)

Provenance and peer review Not commissioned; externally peer reviewed.

\section{REFERENCES}

1. Wood BH, Bilclough JA, Bowron A, et al. Incidence and prediction of falls in Parkinson's disease. J Neurol Neurosurg Psychiatry 2002;72:721-5.

2. Tinetti ME, Speechley M, Ginter SF. Risk factors for falls among elderly persons living in the community. N Engl J Med 1988;319:1701-7.

3. Woodford H, Walker R. Emergency hospital admissions in idiopathic Parkinson's disease. Mov Disord 2005:20:1104-8.

4. Davey C, Wiles R, Ashburn A, et al. Falling in Parkinson's disease: the impact on informal caregivers. Disabil Rehabil 2004;26:1360-6.

5. Schrag A, Hovris A, Morley D, et al. Caregiver burden in Parkinson's disease is closely associated with psychiatric symptoms, falls and disability. Parkinsonism Relat Disord 2006;12:35-41.

6. Parkinson's Disease Society. Life with Parkinson's disease today-room for improvement. London: Parkinson's Disease Society, 2008.

7. Gillespie LD, Robertson MC, Gillespie WJ, et al. Interventions for preventing falls in older people living in the community. Cochrane Database Syst Rev 2009;2: CD007146.

8. Goodwin VA, Richards SH, Taylor RS, et al. The effectiveness of exercise interventions for people with Parkinson's disease: a systematic review and metaanalysis. Mov Disord 2008;23:631-40. 
9. Ashburn A, Fazakarley L, Ballinger $\mathrm{C}$, et al. A randomised controlled trial of a homebased exercise programme to reduce risk of falling among people with Parkinson's disease. J Neurol Neurosurg Psychiatry 2007;78:678-84.

10. Chang JT, Morton SC, Rubenstein LZ, et al. Interventions for the prevention of falls in older adults: systematic review and meta-analysis of randomised clinical trials. BMJ 2004:328:680-6.

11. Sherrington C, Whitney JC, Lord SR, et al. Effective exercise for the prevention of falls: a systematic review and meta-analysis. J Am Geriatr Soc 2008;56:2234-43.

12. National Institute for Health and Clinical Excellence. Parkinson's disease: diagnosis and management in primary and secondary care. London: Royal College of Physicians, 2006; report No CG35.

13. Dinan SM, Skelton DA. Exercise for the prevention of falls and injuries in frailer older people: a manual for the postural stability instructor. 3rd edn. London: Later Life Training, 2007.

14. Skelton D, Dinan S, Campbell M, et al. Tailored group exercise (Falls Management Exercise-FaME) reduces falls in community-dwelling older frequent fallers (an RCT). Age Ageing 2005;34:636-9.

15. Lamb SE, Jorstad-Stein EC, Hauer K, et al. Development of a common outcome data set for fall injury prevention trials: the Prevention of Falls Network Europe Consensus. J Am Geriatr Soc 2005:53:1618-22.

16. Goodwin VA, Richards SH, Campbell JL. Exploring a targeted exercise intervention to reduce falls in people with Parkinson's disease. Agility 2007;2:4-7.

17. Yardley L, Beyer N, Hauer K, et al. Development and initial validation of the Falls Efficacy Scale-International (FES-I). Age Ageing 2005;34:614-19.

18. Euro0ol Group. EuroOol-a new facility for the measurement of health-related quality of life. Health Policy 1990;16:199-208.

19. Gill DP, Jones GR, Zou GY, et al. The Phone-FITT: a brief, valid and reliable physical activity interview with older adults. J Aging Phys Act 2008;16:292-315.

20. Berg KO, Wood-Dauphinee SL, Williams Jl, et al. Measuring balance in the elderly: validation of an instrument. Can J Public Health 1992;83:S7-11.

21. Podsiadlo D, Richardson S. The timed "up and go": a test of basic functional mobility for frail elderly persons. J Am Geriatr Soc 1991;39:142-8.

22. Campbell AJ, Robertson MC, Gardner MM, et al. Randomised controlled trial of a general practice programme of home based exercise to prevent falls in elderly women. BMJ 1997;315:1065-9

23. Donaldson MG, Sobolev B, Cook WL, et al. Analysis of recurrent events: a systematic review of randomised controlled trials of interventions to prevent falls. Age Ageing 2009;38:151-5

24. Lee KJ, Thompson SG. Clustering by health professional in individually randomised trials. BMJ 2005;330:142-4.

25. ICH Expert Working Group. ICH Harmonised Tripartite Guideline. Statistical principles for clinical trials. International Conference on Harmonisation E9 Expert Working Group. Stat Med 1999;18:1905-42.
26. Allen NE, Canning CG, Sherrington $\mathrm{C}$, et al. The effects of an exercise program on fall risk factors in people with Parkinson's disease: a randomised controlled trial. Mov Disord 2010;25:1217-25

27. Quinn L, Busse M, Khalil H, et al. Client and therapist views on exercise programmes for early-mid stage Parkinson's disease and Huntington's disease. Disabil Rehabil 2010:32:917-28.

28. Ravenek MJ, Schneider MA. Social support for physical activity and perceptions of control in early Parkinson's disease. Disabil Rehabil 2009:31:1925-36.

29. Schmitz-Hubsch T, Pyfer D, Kielwein K, et al. Qigong exercise for the symptoms of Parkinson's disease: a randomised controlled pilot study. Mov Disord 2006;21:543-8.

30. Schulz KF, Chalmers I, Hayes RJ, et al. Empirical evidence of bias. Dimensions of methodological quality associated with estimates of treatment effects in controlled trials. JAMA 1995;273:408-12.

31. Office for National Statistics. National statistics: ethnicity and identity. http://www.statistics.gov.uk/cci/nugget.asp?id=456 2001 (accessed 8 October 2009)

32. Hawe P, Shiell A, Riley T. Complex interventions: how "out of control" can a randomised controlled trial be? BMJ 2004;328:1561-3

33. Donoghue D, Stokes EK. How much change is true change? The minimal detectable change of the Berg balance scale in elderly people. J Rehabil Med 2010; 41:343-6.

34. Nieuwboer A, Kwakkel G, Rochester L, et al. Cueing training in the home improves gait-related mobility in Parkinson's disease: the RESCUE trial. J Neurol Neurosurg Psychiatry 2007;78:134-40.

35. Morris ME, lansek R, Kirkwood B. A randomized controlled trial of movement strategies compared with exercise for people with Parkinson's disease. Mov Disord 2009;24:64-71.

36. Ramaswamy B, Jones D, Goodwin V, et al. Quick reference cards (UK) and guidance notes for physiotherapists working with Parkinson's disease. London: Parkinson's Disease Society, 2009.

37. Gladman J, Radford KA, Edmans JA, et al. Specialist rehabilitation for neurological conditions: literature review and mapping study. London: NHS SDO R\&D programme, 2007.

38. Medical Research Council. Developing and evaluating complex interventions: new guidance. London: Medical Research Council, 2008. http://www.mrc.ac.uk/ complexinterventionsguidance.

39. Canning C, Sherrington C, Lord S, et al. Exercise therapy for prevention of falls in people with Parkinson's disease: a protocol for a randomised controlled trial and economic evaluation. BMC Neurol 2009;9:4.

40. Watts JJ, McGinley JL, Huxham F, et al. Cost effectiveness of preventing falls and improving mobility in people with Parkinson disease: protocol for an economic evaluation alongside a clinical trial. BMC Geriatr 2008;8:23. 